\title{
Non-linear growth models for Beetal goats
}

\author{
Shakeel Nouman ${ }^{1 *}$ and Yasir Abrar ${ }^{2}$ \\ ${ }^{1}$ Livestock Production Research Institute Bahadurnagar (Okara), Pakistan. \\ ${ }^{2}$ Livestock Experimental Station, Bahadurnagar (Okara), Pakistan.
}

Accepted 26 March, 2013

\begin{abstract}
The data were taken from the "Enhancing of Mutton Production through goat breeding" a Project run at Livestock Production Research Institute Bahadurnagar (Okara); the growth performance of Beetal goats were compared by statistical non-linear models, like Exponential, Gompertz and Logistic models. These models were based to obtain the best fitted model by following the criteria of mean absolute error (MAE), root mean squared error (RMSE), and mean absolute percentage error (MAPE). Run test were used to check the independence and normality of the models and residuals were checked by Shapiro Wilk test. Errors were found to be normal and independently distributed. Body weights of Beetal goats and Bucks were examined by shape of the curves and it revealed that the values of $\alpha, \beta$ and $y$ of Gompertz model were higher than that of exponential and logistics in both the district of Okara and Sahiwal. Also, values of MAE, RMSE and MAPE of Gompertz model were lower than the logistic and exponential.
\end{abstract}

Key words: Bodyweight of Beetal, Gompertz, least value.

\section{INTRODUCTION}

The knowledge of growth curves in Beetal goats was important for determining the biological, genetic and economical efficiencies (Mehta et al., 1997). Appropriate models fitted to the data may be used for future planning to take early maturity better growth rate, weight gain in Beetal goats (Karna et al., 2001). This information may be useful for planning of future meat production in Pakistan.

Non-linear models have been used for, balancing the protein, feed intake, digestion; growth rate for this best suited model was exponential models, evaluation (Kohn et al., 1998; Bruce et al., 2001; Shah and Muphy, 2006). The animal growth data were generally non-linear in nature. From the available literature, very few examples have been seen to study growth of Beetal goats using non-linear model. In this paper, it seems that no attempt has been made to study growth of Beetal goats using non-linear models (Hasnain, 1985). The data from the body weights of Beetal goats were plotted on exponential, logistic and Gompertz, the value obtained reveled that Gompertz model was the best suitable than the other.

\section{MATERIALS AND METHODS}

The study was conducted in two Districts of Punjab provinces, that is, Okara and Sahiwal in Pakistan. The observations about body weight in kilograms of Beetal goats were taken from above areas. In both District, Experimental Stations Government farms were selected and all recordings were done at flocks of Beetal at farms. The data obtained from male and female Beetal breeds were plotted first separately and the shape of the curve examined. The data was collected on weekly basis, pre-weaning, and birth to eight weeks of age. The data were taken four times in a month from Livestock farms of Beetal goats till the years 2007 to 2009 in Okara and Sahiwal Districts of Punjab, Pakistan. Since this weekly data were used as month average weight gain. The data of 48 Beetal 
Table 1. Estimates and measures of fitted models for male and female Beetal goats at Okara and Sahiwal District.

\begin{tabular}{|c|c|c|c|c|c|c|c|c|c|}
\hline District & Year & Sex & Model & $\alpha$ & $\beta$ & $y$ & MAE & RMSE & MAPE \\
\hline \multirow{14}{*}{ Okara } & \multirow{8}{*}{2007 to 2008} & \multirow{3}{*}{ Male } & Exponential & 4.61 & -0.06 & - & 2.60 & 3.71 & 26.55 \\
\hline & & & Gompertz & 27.62 & 2.54 & 0.10 & 1.30 & 2.18 & 18.42 \\
\hline & & & Logistic & 7.67 & 0.17 & 24.74 & 1.67 & 2.61 & 21.56 \\
\hline & & & & & & & & & \\
\hline & & \multirow{3}{*}{ Female } & Exponential & 4.58 & -0.06 & 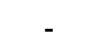 & 2.59 & 3.64 & 24.02 \\
\hline & & & Gompertz & 29.33 & 2.53 & 0.09 & 1.38 & 2.51 & 19.87 \\
\hline & & & Logistic & 8.29 & 0.16 & $25.9 !$ & 1.77 & 3.00 & 23.26 \\
\hline & & & & & & & & & \\
\hline & \multirow{6}{*}{2008 to 2009} & \multirow{3}{*}{ Male } & Exponential & 4.26 & -0.08 & - & 2.90 & 5.60 & 27.85 \\
\hline & & & Gompertz & 135.1 & 3.85 & 0.04 & 0.79 & 0.97 & 2.24 \\
\hline & & & Logistic & 17.41 & 0.12 & 61.14 & 1.24 & 1.73 & 6.83 \\
\hline & & \multirow{3}{*}{ Female } & Exponential & 3.96 & -008 & & 2.86 & 6.17 & 27.04 \\
\hline & & & Gompertz & 63.3 & 5.33 & 0.023 & 1.21 & 1.77 & 05.86 \\
\hline & & & Logistic & 29.00 & 0.11 & 102.8 & 1.07 & 1.30 & 02.74 \\
\hline \multirow{12}{*}{ Sahiwal } & \multirow{6}{*}{2007 to 2008} & \multirow{3}{*}{ Male } & Exponential & 5.97 & -0.07 & - & 4.58 & 6.15 & 39.26 \\
\hline & & & Gompertz & 48.85 & 3.51 & 0.11 & 0.60 & 0.18 & 03.45 \\
\hline & & & Logistic & 16.28 & 0.21 & 42.44 & 087 & 1.26 & 08.35 \\
\hline & & \multirow{3}{*}{ Female } & Exponential & 6.61 & -0.07 & - & 4.50 & 5.81 & 35.57 \\
\hline & & & Gompertz & 46.47 & 3.40 & 011 & 0.62 & 0.92 & 06.46 \\
\hline & & & Logistic & 14.79 & 0.21 & 11.05 & 0.97 & 1.52 & 10.87 \\
\hline & \multirow{6}{*}{2008 to 2009} & \multirow{3}{*}{ Male } & Fxnonential & 6.28 & -0.78 & - & 3.32 & 432 & 1868 \\
\hline & & & Gompertz & 95.93 & 3.36 & 0.06 & 1.62 & 2.13 & 08.94 \\
\hline & & & Logistic & 14.43 & 0.14 & 66.79 & 2.10 & 2.75 & 11.94 \\
\hline & & \multirow{3}{*}{ Female } & Exponential & 5.67 & -0.07 & - & 2.97 & 3.92 & 20.64 \\
\hline & & & Gompertz & 78.27 & 3.27 & 0.62 & 1.25 & 1.65 & 07.85 \\
\hline & & & Logistic & 13.60 & 0.14 & 55.87 & 1.72 & 2.19 & 10.81 \\
\hline
\end{tabular}

bucks and 57 female Beetal goats for the period of 36 weeks in Okara Districts of Punjab, Pakistan were studied (Table 1). In Sahiwal District of Pakistan, 49 male bucks and 38 female Beetal goats for period of 32 weeks were under observations in this way total 68 weeks (16 months) time period Beetal of certain Farms are under observation and data collected from them.

\section{Exponential model}

This model can be represented by:

$E\left(Y_{t}\right)=\alpha e^{-\beta t}$

Where, $Y_{t}$ denotes the body weight at time $t, \alpha(>0)$ is the value of $Y_{t}$ at the time $t=0$ and $\beta$ is the exponential rate of growth over time and $E$ represents the expected value of body weight (Balakrishnan and Jain, 1988).

\section{Logistic model}

$Y_{t}$ denotes the response variable under study (body weight) at time $t, \alpha(>0)$ denotes intrinsic growth rate and $y$, the ceiling value. Then this model is represented by:

$E\left(Y_{t}\right)=Y /\left(1+e^{\wedge}(-\alpha t)\right)$
Where $\beta=\left(Y-Y_{0}\right) / Y_{0}$ and $Y_{0}$ is the value of $Y_{t}$ at $t=0$

\section{Gompertz model}

This model is represented by:

$E\left(Y_{t}\right)=\gamma \exp [-\beta \exp (-\alpha t)]$

where symbols have same meaning as in logistic model. Both the Logistic and Gompertz models are of sigmoid shape. The difference between the two is that Logistic is symmetric while Gompertz model is not symmetric about the point of inflection.

\section{Criteria for model selection}

There are situations in which the use of model is not particularly well founded and several competing models may appear to fit the data equally well in practice. Hence, there is a need to know the criteria that will help us to test the goodness of fit vis-a-vis comparison among different competing models. The three most prominent criteria of fitting the models are used here. These criteria are mean absolute error (MAE), root mean squared error (RMSE) and mean absolute percentage error (MAPE). The description and properties of these criteria are available in community on error measure (Ahlburg, 1992). 
Table 2. Shapiro-Wilk's and Run-test for testing normality and randomness of residuals.

\begin{tabular}{|c|c|c|c|c|c|c|c|}
\hline \multirow{2}{*}{ District } & \multirow{2}{*}{ Year } & \multirow{2}{*}{ Sex } & \multicolumn{2}{|c|}{ Shapiro-Wilk's test } & \multirow{2}{*}{ Total cases } & \multicolumn{2}{|c|}{ Run-test } \\
\hline & & & Statistics-W & $\operatorname{Pr}<W$ & & No. of runs & $\operatorname{Pr}<Z$ \\
\hline \multirow{4}{*}{ Okara } & \multirow{2}{*}{2007 to 2008} & Male & 0.9834 & 0.9848 & 16 & 5 & 0.076 \\
\hline & & Female & 0.9738 & 0.8958 & 16 & 5 & 0.076 \\
\hline & \multirow{2}{*}{2008 to 2009} & Male & 0.9491 & 0.4754 & 16 & 5 & 0.070 \\
\hline & & Female & 0.9536 & 0.5494 & 16 & 6 & 0.267 \\
\hline \multirow{4}{*}{ Sahiwal } & \multirow{2}{*}{2007 to 2008} & Male & 0.9037 & 0.1085 & 15 & 6 & 0.290 \\
\hline & & Female & 0.9764 & 0.9386 & 15 & 6 & 0.478 \\
\hline & \multirow{2}{*}{2008 to 2009} & Mate & 0.9751 & 0.9252 & 15 & 6 & 0.341 \\
\hline & & Female & 0.9410 & 0.3954 & 15 & 6 & 0.290 \\
\hline
\end{tabular}

The selection of model was made on the basis of minimum value of MAPE, RMSE and MAE and also on the valid estimates of parameters (Wang and Zuidhof, 2004). To work out percentage prediction error, the curve was fitted up-to 28 weeks of age and error was predicted for 32 and 36 weeks of age. Further, the best fit models were tested for independence and normality of the residuals. For randomness of residuals run test (Syariffudin et al., 2006) and for testing the normality of the residuals Shapiro-Wilks test statistic (Royston, 1982; Shaprio and Wilk, 1965) were applied. As the work done by Takma et al. (2004) describe the growth curve of turkey toms using Gompertz model had found similar observations as in our work. Thus, Gompertz model was observed to be best fit for male Beetal goats at Okara District.

\section{RESULTS AND DISCUSSION}

The results obtained from Okara District for male bucks indicated that the values $\alpha, \beta$ and $y$ for Gompertz model were $27.62,2.54,0.10$, the values for exponential and logistic were 4.61, 0.06, 0.00 and 7.67, 0.17, 24.74, respectively. Also, MAPE, MAE and RMSE were 18.42, 1.30 , and 2.18 of Gompertz model while the value of exponential and logistic of MAPE, MAE and RMSE were 26.55, 2.60, 3.71 and 21.56, 1.67, 2.61, respectively.

Female Beetal goats indicated that the values for Gompertz model were $\alpha, \beta$ and $\gamma$ were $29.33,2.53,0.09$, the values for Exponential and Logistic models were $4.58,0.06,0.00$ and $8.29,0.16,25.91$, respectively. In female Beetal goats, the value of Gompertz for MAPE, MAE and RMSE were 19.87, 1.38, and 2.51 while the value of exponential and logistic of MAPE, MAE and RMSE were 24.02, 2.59, 3.64 and 23.26, 1.77, 3.00, respectively (Table 1 ).

Same results obtained from Sahiwal districts, that is, the value of Gompertz model for $\alpha, \beta$ and $y$ is higher than the exponential and logistic while values of MAPE, MAE and RMSE were lower than the values of exponential and logistic models.

These results were similar to Takma et al. (2004) which revealed that Gompertz model was best fitted on growth pattern. In this model, the estimates of the parameters were in the valid range; however, in all cases this is according to the view point of Wang et al. (2004).

The best fitted models were tested for independence and normality of the residuals was described in Table 2. The results obtained from both the district to check for normality we use Shapiro-Wilk's test and see that the values of statistics-w for male and female was 0.9 approximately $\operatorname{Pr}<w^{\prime}$. Also to check the randomness, we apply run test and see that residuals were distributed independently as the two tailed probability is more than 0.05 in all the cases in run-test, the $\mathrm{Pr}<\mathrm{z}$ statistics (Shapiro and Wilk, 1972; Royston, 1982).

Thus, Logistic model was the good fit than the exponential in this case; Szydat and Lien (2001) describe the logistic model for better estimates. Thus, Logistic model would be next better in this case also to describe the application of nonlinear models toward animal feeding programs are discussed (Mark et al., 2010).

\section{REFERENCES}

Ahlburg D (1992). A Commentary on Error Measures: Error Measures and Choice of a Forecast Method. Int. J. Forecasting 8:99-111.

Balakrishnan KA, Jain JP (1988). Exponential-quadratic regression model for the analysis of non-linear $G \times E$ interactions in vegetable crops. Ann. Agric. Res. 9:229-233.

Bruce HL, Scott JR, Thompson JM (2001). Application of an exponential model to early post morten bovine muscle PH decline. 58(185):39-44.

Hasnain HU (1985). Sheep and Goats in Pakistan. FAO Animal Production and Health Paper 56. FAO. Rome.

Karna DK, Koul GL, Bisht GS (2001). Birth weight, morphometry and relative gain in body weight of Cheghu kids. Indian J. Anim. Sci. 71(2):180-182.

Kohn RA, Kalscheur KF, Hanigan (1998). Evaluation of models for balancing the protein requirements of dairy cows. J. Dairy Sci. 81(12):3402-3414.

Mark DF, Gene RD, Norlin BJ (2010). Use of four-Permanent logistic model to evaluate the protein quality of mixed of mormon cricket meal and corn gluten meal in rats. Int. J. Poult. Sci. 9(9):916-919.

Mehta BS, Singh D, Khan BU (1997). Genetic studies on growth in Sirohi goats. Indian J. Anim. Sci. 67(8):723-725.

Royston JP (1982). An extension of Shapiro and Wilk's W test for 
normality to large samples. Appl. Stat. 31:115-124.

Shah MA, Muphy MR (2006). Development and evaluation of models to predict the feed intake of dairy cows in early lactation. J. Dairy Sci. 89(1):294-306.

Shapiro SS, Wilk MB (1972). An analysis of variance test for the exponential distribution (complete samples), Technometrics 14:355370.

Syariffudin M, Abdullah R, Abdul SR (2006). Adapting Runs Test as Pattern Generator for Protein Secondary Structure Recognition, 2nd IMT-GT Regional conference on mathematics, statistics and Application University sains Malaysia, Penang, June. pp. 13-15.
Szydat SJH, Lien S (2001). Logistic Regression approach to modeling the variability of recombination rate. J. Anim. Sci. Breed. Genet. 117(1):17-23

Takma C, Özkan S, Akbaş Y (2004). Describing growth curve of turkey toms using Gompertz model. Unit of Animal Husbandry, Dept. Animal Sci. Agric. Fac. Ege Univ. 35100. İzmir Turkey.

Wang Z, Zuidhof MJ (2004). Estimation of Growth Parameters Using a Nonlinear Mixed Gompertz Model. Poult. Sci. 83(6):847-852. 